\title{
The Role of Temperature in the Late-season Decline in Soluble Solids Content of Strawberry Fruit in a Subtropical Production System
}

\author{
Steven J. MacKenzie, Craig K. Chandler, Tomas Hasing, \\ and Vance M. Whitaker ${ }^{1}$ \\ Gulf Coast Research and Education Center, University of Florida, 14625 CR \\ 672, Wimauma, FL 33598
}

Additional index words. fruit development period, truss position

\begin{abstract}
In west-central Florida, strawberries (Fragaria $\times$ ananassa Duch.) are harvested from early December to late March. The peak harvest occurs at the end of the season and lasts $\approx 1$ month, usually from late February to mid-March. As the peak harvest progresses and temperatures increase, fruit become smaller and the soluble solids content (SSC) of fruit declines. The main objective of this study was to determine whether the progression of peak harvest results in a decline in SSC independent of temperature. In 2007 and 2008 , recently opened flowers were tagged in the field on the first week into the peak bloom (WPB) and for 3 additional weeks thereafter. Three days after tagging, plants were transplanted to one of two constant temperature environments $\left(15\right.$ or $\left.22^{\circ} \mathrm{C}\right)$. At maturity, the weight, SSC, and fruit development period (FDP) of tagged fruit were recorded. Fruit SSC was lower at the higher temperature $\left(5.2 \%\right.$ at $22{ }^{\circ} \mathrm{C}$ versus $6.5 \%$ at $15{ }^{\circ} \mathrm{C}$ ) in both years. In 2007, SSC was not correlated with WPB, and in 2008, SSC was positively correlated with WPB at constant temperatures. In addition, the coefficient of determination $\left(r^{2}\right)$ for a regression of SSC on mean temperature over the period 8 days before harvest was 0.73 for fruit harvested from fields between 2003 and 2009. These results indicate that rising temperature is a major factor responsible for the late-season decline of SSC in strawberry fruit in a subtropical production system.
\end{abstract}

The Florida strawberry industry, valued at \$362 million during the 2009-2010 season, is concentrated in subtropical west-central Florida on $\approx 3600$ ha (U.S. Department of Agriculture, 2011). During a typical season, transplants are set in the field in early October and fruit is harvested from the beginning of December to late March. Total fruit yield as well as the average size and the SSC of fruit, which impact perception of fruit quality (Jouquand et al., 2008), fluctuate over the course of the season (MacKenzie and Chandler, 2009). There are typically two or three cycles in which yields rise and then fall (Chandler et al., 1994). Larger primary fruit predominate at the beginning of cycles, whereas smaller fruit predominate later in the cycles (MacKenzie and Chandler, 2009). Fruit size is largely dependent on the predominant order of fruit ripening at any one time (Dana, 1980; Janick and Eggert, 1968). The period lasting from late February to mid-March usually corresponds to the highest yielding cycle and is often described as the peak harvest (Legard et al., 2005). The fruit from the peak harvest result from flowers produced during the period from late January to mid-February, and this period is usually described as the peak bloom.

Received for publication 14 July 2011. Accepted for publication 30 Aug. 2011.

${ }^{1}$ To whom reprint requests should be addressed; e-mailvwhitaker@ufl.edu.
Soluble solids content is the collective concentration of sugars, acids, and other substances dissolved in the cell sap. In strawberry, sugars comprise $80 \%$ to $90 \%$ of the SSC (PerkinsVeazie, 1995). Fruit SSC is usually satisfactory for consumers until a point during the month of March when low SSC decreases fruit quality and contributes to growers' decisions to quit harvesting. Rising temperatures may explain the decline in fruit SSC at the end of the season (Wang and Camp, 2000). However, other factors such as the age of plants, the predominant order of harvested fruit, and increasing yield correlate with the progression of the peak harvest and could affect fruit SSC independently. The ratio of fruit weight to leaf weight has been shown to increase over time, and an increased sink:source ratio could help explain the decline in fruit SSC (Olsen et al., 1985). Although fruit SSC was positively correlated with the incidence of solar radiation in other production systems (Hoppula and Karhu, 2006; Watson et al., 2002), fluctuations in photosynthetically active radiation $(P A R)$ are not likely to have a major effect on fruit SSC in Florida because plant exposure to $P A R$ is increasing late in the season when fruit SSC is declining.

The primary objective of this study was to test the hypothesis that the progression of the peak harvest results in a decline of fruit SSC independent of temperature. This hypothesis was tested over two seasons by moving plants from the field to constant temperature and light environments at different times during the peak bloom period that precedes the peak harvest. Trends in fruit weight and fruit development period over time under the controlled environments were also determined. A second objective was to determine the potential for predicting fruit SSC from atmospheric temperature alone using temperature and fruit SSC data collected during six seasons in Florida.

\section{Materials and Methods}

Plant material. Experiments were conducted on 'Strawberry Festival' strawberry plants grown using the annual plasticulture system at the University of Florida Gulf Coast Research and Education Center in Balm, FL, during two seasons (2006-2007 and 20072008). The soil at this location is characterized as a Myakka fine sand with $\approx 1.5 \%$ organic matter. Beds were $91.5 \mathrm{~m}$ long, $71 \mathrm{~cm}$ wide, $15 \mathrm{~cm}$ high at the edges, and $18 \mathrm{~cm}$ high in the center and were covered with a single layer of black, high-density polyethylene mulch. The distance between bed centers was $1.2 \mathrm{~m}$. Each bed contained two rows of plants spaced $38 \mathrm{~cm}$ apart within rows and $28 \mathrm{~cm}$ apart between rows. The beds were fumigated with a mixture of methyl bromide and chloropicrin before transplanting in October. Bare-root transplants from Quebec, Canada, were set in October and irrigated with overhead sprinklers for $10 \mathrm{~d}$ during daylight hours to facilitate establishment. Once established, plants were irrigated and fertilized exclusively through a single drip tape per bed. Fruit were harvested from plants twice weekly from the beginning of December to the date when plants were moved to a constant temperature environment in 2007 and 2008.

Effects of peak harvest progression on fruit soluble solids content. During the 20062007 and the 2007-2008 seasons, flower counts were monitored to determine the beginning of the peak bloom period that precedes the lateseason peak harvest cycle. On the first Friday of the peak bloom, 26 Jan. 2007 for the 20062007 season and 8 Feb. 2008 for the 2007-2008 season, 48 plants with recently opened flowers on a single bed were marked with a stake. A weatherproof plastic tag was placed around the stem of open flowers (two to six flowers/plant) on 12 of the 48 plants on 26 Jan., 2 Feb., 9 Feb., and 16 Feb. in 2007 and 8 Feb., 15 Feb., 22 Feb., and 29 Feb. in 2008. Within each season, these dates correspond to the Friday of Weeks $1,2,3$, and 4 of the peak bloom (WPB). The majority of anthers on tagged flowers displayed no signs of senescence, indicating the maximum time that the flowers could have been open was less than $2.5 \mathrm{~d}$ (MacKenzie and Chandler, 2009). Plants with tagged flowers were left in the field for $3 \mathrm{~d}$ to facilitate pollination and then transplanted to 7.7-L (10 Standard) pots (Belden Plastics, Roseville, $\mathrm{MN})$. Soil surrounding the roots comprised most of the pot volume. The remaining volume was filled with soilless potting mix (2 Mix; Conrad Fafard Inc., Agawa, MA).

Potted plants were placed overnight in a growth room with a 12-h day/night cycle at 
$15^{\circ} \mathrm{C}$. The next day, six of the 12 plants were moved to a $22{ }^{\circ} \mathrm{C}$ growth room with a 12 -h day/ night cycle. Immediately after transplanting, some visible loss of turgor was observed, but this was not evident $20 \mathrm{~h}$ later. Growth rooms contained fluorescent lighting $\left(180 \mu \mathrm{mol} \cdot \mathrm{m}^{-2} \cdot \mathrm{s}^{-1}\right.$ photosynthetically active photon flux), which produced net photosynthetic activity $\approx 50 \%$ of the maximum possible rate at normal atmospheric $\mathrm{CO}_{2}$ levels (Chabot, 1978; Ferree and Stang, 1988). Plants were watered when needed and monitored daily for ripe fruit. Ripeness was defined as the stage at which the fruit became fully colored from tip to calyx.

When a tagged fruit ripened, the harvest date was recorded, the fruit was weighed, and the SSC (\%) of the fruit juice was measured at room temperature with a digital refractometer that was standardized with deionized water (Atago Co., Tokyo, Japan). To obtain juice for SSC measurements, each fruit was pressed in a potato ricer, and the expressed juice was filtered once through $1.5-\mathrm{mm}$ wire mesh. The FDP of each fruit was the number of days from tagging to harvest. Untagged fruit that ripened between transplanting and when the final tagged fruit was harvested were also harvested and the number recorded. This gave an estimate of the total number of flowers and green fruit on the plant at the time of tagging. The mean weight of the tagged fruit was multiplied by the total number of tagged and untagged fruit to construct an estimated yield variable for the constant temperature environment, which was used as a covariate in the analysis.

Concurrent with the controlled temperature experiments, plants of 'Strawberry Festival' that remained in the field were harvested during the peak bloom period to determine trends in marketable yield (g/plant), mean fruit weight $(\mathrm{g})$, and SSC in the field. Yield data from plants grown in four replicate plots (10 plants/plot) are reported for four consecutive 1 -week intervals each season. The first harvest interval corresponded to when the first set of tagged flowers would have ripened had they remained in the field as determined by a yield model taking into account atmospheric temperature (MacKenzie and Chandler, 2009). This harvest occurred $28 \mathrm{~d}$ after tagging in 2007 and $24 \mathrm{~d}$ after tagging in 2008. Soluble solids content and fruit weight were recorded for 10 randomly selected fruit during each sampling interval.

In a statistical analysis of the constant temperature experiments using data from both years combined, the independent variables year, WPB, temperature, plant (year $\times$ WPB $\times$ temperature), year $\times$ temperature, year $\times$ WPB, $\mathrm{WPB} \times$ temperature, and year $\times$ temperature $\times$ WPB were used to explain variation in the dependent variables FDP, fruit weight, and SSC. Additional analyses were performed examining data from each year separately when interactions with year were evident. For these analyses, the independent variables were WPB, temperature, plant (WPB $\times$ temperature), and $\mathrm{WPB} \times$ temperature. All independent variables were fixed effects, except the variables plant (year $\times$ WPB $\times$ temperature) and plant (WPB $\times$ temperature), which were random effects. The nested plant effect was included in models to account for correlation of measurements from plants assigned to each of the 16 possible season $\times$ WPB $\times$ temperature combinations. The dependent variable SSC was modeled with and without estimated yield as a covariate. The models that included the covariate were estimated on a plant mean basis and therefore did not contain the nested plant terms. Effects were described as significant if $P>F$ was less than 0.05 . In all analyses, the linear, quadratic, and cubic components of variation attributable to WPB were evaluated by polynomial contrast. The statistical analyses were conducted using PROC MIXED in SAS 9.1 (SAS Institute, Cary, NC) with covariance parameters estimated by restricted maximum likelihood.

Construction of a model to predict fruit soluble solids content based on air temperature. To construct a model to predict fruit SSC based on air temperature, fruit SSC was measured on 26 dates over six seasons (20032004, 2006-2009) in Florida between 1 Jan. and 30 Mar. Some SSC measurements were obtained from the literature. Mean SSC for fruit grown in Dover, FL, on four dates in 2003 and 2004 was published by Del Pozo-Insfran et al. (2006) and mean SSC in Wimauma, FL, on five dates in 2006 and 2007 was published by Jouquand et al. (2008). In 2007 and 2008, mean SSC was obtained from the concurrent field experiment previously described. In 2009, SSC was measured on nine dates separated by 1 week beginning on $2 \mathrm{Feb}$.
Means on each date were determined from at least eight fruit with the exception of a mean for 23 Feb. 2009 that was calculated from three fruit. Mean SSC readings were correlated with mean $60-\mathrm{cm}$ aboveground temperature over periods ranging from 1 to $21 \mathrm{~d}$ before harvest. Mean temperature during the 8-d period before harvest had the highest coefficient of determination $\left(r^{2}\right)$ and was selected for inclusion in the model. Subsequently, mean solar radiation values over intervals from 1 to $21 \mathrm{~d}$ were evaluated in a multiple regression analysis along with the mean 8-d temperature before harvest. Temperature and solar radiation data were obtained from a weather station directly adjacent to the plots, which was part of the Florida Automated Weather Network (University of Florida, 2009). All regression analyses were done using the statistics program SAS 9.1 (SAS Institute).

\section{Results and Discussion}

Trends in yield, fruit weight, and soluble solids content in the field. In 2007 and 2008, there was a steady increase in marketable yield during the peak harvest despite a decrease in average fruit weight (Fig. 1). In 2007, SSC decreased over this same period from a mean of $9.0 \%$ at $1 \mathrm{WPB}$ to $5.6 \%$ at $4 \mathrm{WPB}(P<$ $0.001)$. In 2008, the range in SSC was much narrower, from $7.0 \%$ at $1 \mathrm{WPB}$ to $6.5 \%$ at 4 WPB, and the change was not significant $(P=$ 0.101) (Fig. 1). In 2008, an advective freeze event occurred 5 weeks before flowers were
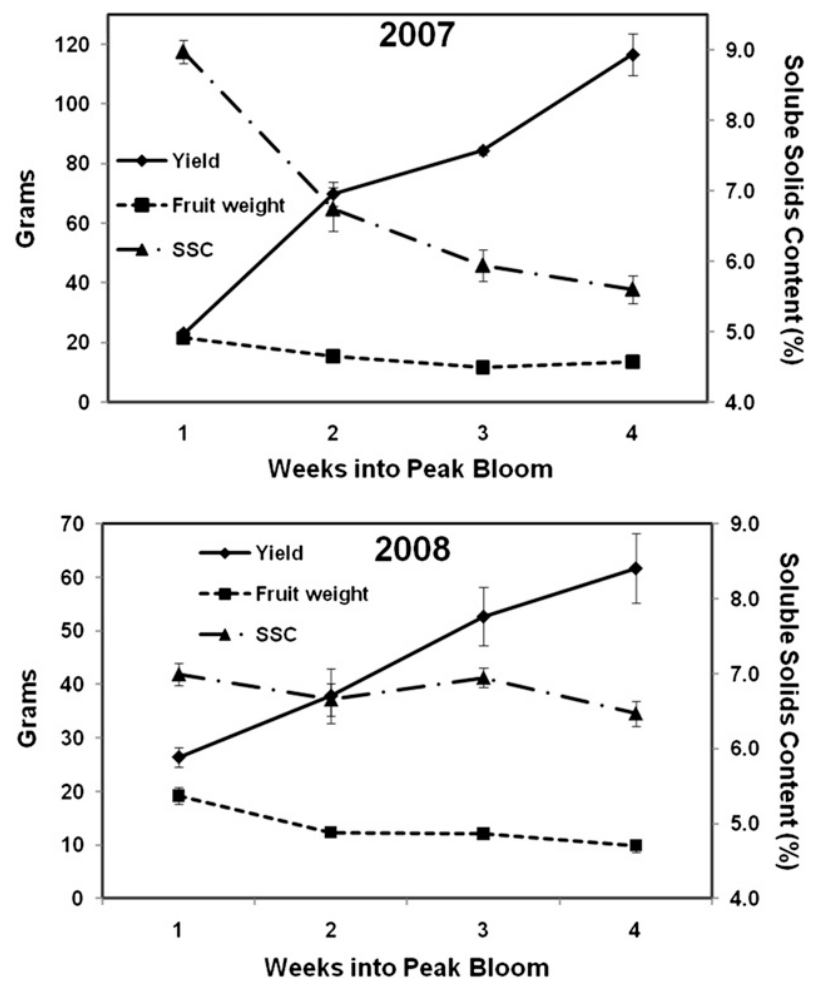

Fig. 1. Mean marketable yield ( $\mathrm{g} / \mathrm{plant}$ ), fruit weight ( $\mathrm{g} /$ fruit), and soluble solids content (\%) of 'Strawberry Festival' fruit harvested from plants growing in the field in 2007 and 2008. Fruit harvest in the field was timed to coincide with the ripening of fruit from flowers tagged in the controlled temperature experiment. Flowers were tagged on dates ranging from 1 to 4 weeks since the beginning of peak bloom and are described by the variable weeks into peak bloom (WPB). Error bars represent SES. 
tagged. This freeze event on 3 Jan. 2008 lasted $10 \mathrm{~h}$, and ambient air temperatures declined to $-2.6{ }^{\circ} \mathrm{C}$. Plants were overhead-irrigated to protect them from damage during this period. However, high winds made the frost protection ineffective and damage to the foliage of plants was obvious. Such events occur approximately once or twice each decade. Leaves contain the largest amount of nonstructural carbohydrates in strawberry, and the leaf area of the plant expands after a bloom is initiated (Schaffer et al., 1986). Damage to the canopy before bloom and subsequent recovering after the bloom was initiated could possibly help account for the absence of a significant decrease in SSC in the field in 2008. In addition, 8-d mean temperatures for the periods before fruit harvest were more uniform in 2008 than in 2007. In 2007, the minimum 8-d mean temperature was 11.6 and it ranged from 17.5 to 20.3 for other harvest dates. In 2008, the minimum 8-d mean temperature was 16.8 and it ranged from 18.4 to 21.1 for other harvest dates. For both years, WPB 1 had the lowest 8-d mean temperature.

Effect of weeks into peak bloom on fruit soluble solids content in a constant temperature environment. A negative relationship between fruit SSC and WPB under a constant temperature environment would support the hypothesis that the progression of the peak harvest results in a decline of fruit SSC independent of temperature. This was not observed. There was a significant year $\times$ WPB interaction indicating that the trend was different between years (Table 1). When years were analyzed separately, WPB did not have a significant effect on fruit SSC in 2007 (Table 1; Fig. 2A). In 2008, the effect was significant and there was a positive linear correlation between WPB and SSC (Table 1; Fig. 2A). Other factors affecting fruit SSC were temperature and year (Table 1). Mean SSC values were lower at $22{ }^{\circ} \mathrm{C}(5.35 \%$ in 2007 and $4.97 \%$ in 2008$)$ than they were at $15{ }^{\circ} \mathrm{C}(6.6 \%$ in 2007 and $6.4 \%$ in 2008). This was consistent with Wang and Camp (2000) who showed that fruit SSC was negatively correlated with post-bloom air temperature. Although mean SSC was lower at both temperatures in 2008, there was no evidence for a year $\times$ temperature effect (Table 1). The PAR in the growth rooms was lower than ideal $\left(180 \mu \mathrm{mol} \cdot \mathrm{m}^{-2} \cdot \mathrm{s}^{-1}\right.$ photosynthetically active photon flux), possibly resulting in reduced net photosynthesis during fruit development and reduced SSC. However, this potential reduction would occur at all temperature regimes and time points and would not be expected to affect the conclusions of the study. Immediately after transplanting, the plants underwent a brief loss of turgor but thereafter resumed normal growth and development. The potential impacts of such stress on fruit SSC are not known and are unlikely to have impacted the observed trends.

Temperature may cause a decline in fruit SSC by altering the balance of physiological processes in plant and fruit tissues. Sugar concentrations in fruit are dependent on rates of uptake by the fruit tissue, fruit photosynthesis,

Table 1. Mixed model analysis of variance $P$ values for effects of year, temperature, and weeks into the peak bloom (WPB) on fruit weight, fruit development period (FDP), and soluble solids content (SSC) of 'Strawberry Festival' fruit from plants after transplantation from a field to a constant temperature environment at different times during the season.

\begin{tabular}{|c|c|c|c|c|}
\hline Source of variation & $d f_{\text {num }}, d f_{d e n}{ }^{\mathrm{y}}$ & $\mathrm{Wt}(\mathrm{g})^{\mathrm{x}}$ & $\operatorname{FDP}(d)^{\mathrm{w}}$ & $\operatorname{SSC}(\%)^{\mathrm{v}}$ \\
\hline \multicolumn{5}{|l|}{2007 and 2008 combined } \\
\hline Estimated yield & 1,76 & - & - & 0.701 \\
\hline Year (2007 versus 2008) & 1,77 & 0.522 & 0.382 & 0.035 \\
\hline Temperature $\left(22\right.$ versus $\left.15^{\circ} \mathrm{C}\right)$ & 1,77 & 0.610 & $<0.001$ & $<0.001$ \\
\hline WPB (Levels 1, 2, 3, and 4) & 3,77 & $<0.001$ & 0.002 & $<0.001$ \\
\hline Year $\times$ temperature & 1,77 & 0.169 & 0.010 & 0.653 \\
\hline Year $\times$ WPB & 3,77 & 0.635 & 0.083 & $<0.001$ \\
\hline Temperature $\times$ WPB & 3,77 & 0.611 & 0.569 & 0.718 \\
\hline Year $\times$ temperature $\times$ WPB & 3,77 & 0.204 & 0.660 & 0.529 \\
\hline \multicolumn{5}{|l|}{$2007^{z}$} \\
\hline Estimated yield & 1,38 & - & - & 0.593 \\
\hline Temperature $\left(22\right.$ versus $\left.15^{\circ} \mathrm{C}\right)$ & 1,39 & & $<0.001$ & $<0.001$ \\
\hline WPB (Levels 1, 2, 3, and 4) & 3,39 & & 0.015 & 0.177 \\
\hline Temperature $\times$ WPB & 3,39 & & 0.915 & 0.596 \\
\hline \multicolumn{5}{|l|}{$2008^{z}$} \\
\hline Estimated yield & 1,37 & & - & 0.983 \\
\hline Temperature $\left(22\right.$ versus $\left.15^{\circ} \mathrm{C}\right)$ & 1,38 & & $<0.001$ & $<0.001$ \\
\hline WPB (Levels 1, 2, 3, and 4) & 3,38 & & 0.012 & $<0.001$ \\
\hline Temperature $\times$ WPB & 3,38 & & 0.379 & 0.678 \\
\hline
\end{tabular}

${ }^{\mathrm{z} F D P}$ and SSC values from 2007 and 2008 were analyzed separately as a result of significant year $\times$ temperature and year $\times$ WPB effects.

${ }^{\mathrm{y}} d f_{\text {num }}$ and $d f_{\text {den }}$ indicate the number of df for the numerator and denominator error terms used to derive $F$ statistics. Degrees of freedom for the denominator in the SSC model including the covariate are 76 for years combined and 38 for 2007 and 37 for 2008 .

${ }^{\mathrm{x}} \sigma^{2}$ plant(year $\times$ temperature $\times$ transplant date) $=4.339$ and $\sigma^{2}$ residual $=9.113$ for years combined.

${ }^{\mathrm{w}} \sigma_{\text {plant }(\text { year } \times \text { temperature } \times \text { transplant date })}^{2}=1.220$ and $\sigma_{\text {residual }}^{2}=5.972$ for years combined. For years analyzed separately: $\sigma_{\text {plant(temperature } \times \text { transplant date) }}^{2}=1.194$ and $\sigma_{\text {residual }}^{2}=5.981$ for 2007 and $\sigma_{\text {plant(temperature } \times}^{2}$ transplant date) $=1.246$ and $\sigma_{\text {residual }}^{2}=5.963$ for 2008 .

${ }^{\mathrm{v}} \sigma_{\text {residual }}^{2}=0.490$ for years combined. For years analyzed separately: $\sigma_{\text {residual }}^{2}=0.466$ for 2007 and $\sigma_{\text {residual }}^{2}=0.526$ for 2008 .

and fruit respiration. Uptake is dependent on carbohydrate supply and the expression and activity of sugar transporters and/or sugarmetabolizing enzymes in the fruit (Forney and Breen, 1986; Saur, 2007). Sucrose uptake was positively correlated with temperatures up to $40{ }^{\circ} \mathrm{C}$ in tissue disks cut from fruit (Forney and Breen, 1986), but it is not clear if prolonged exposure could alter the expression of enzymes required for transport or if substrate concentrations in source tissues are reduced in response to higher temperatures. Fruit respiration is also positively correlated with temperature and may be more responsive to temperature changes than sugar transport (Haller et al., 1941). The contribution of fruit photosynthesis to sugar accumulation in fruit is not likely to be significant (Blanke, 2002). Between 15 and $25{ }^{\circ} \mathrm{C}$ (common daytime temperatures in Florida during the strawberry fruiting season), net photosynthesis was not very sensitive to temperature in Fragaria vesca, and at higher temperatures, net photosynthesis declined (Chabot, 1978). This indicates that
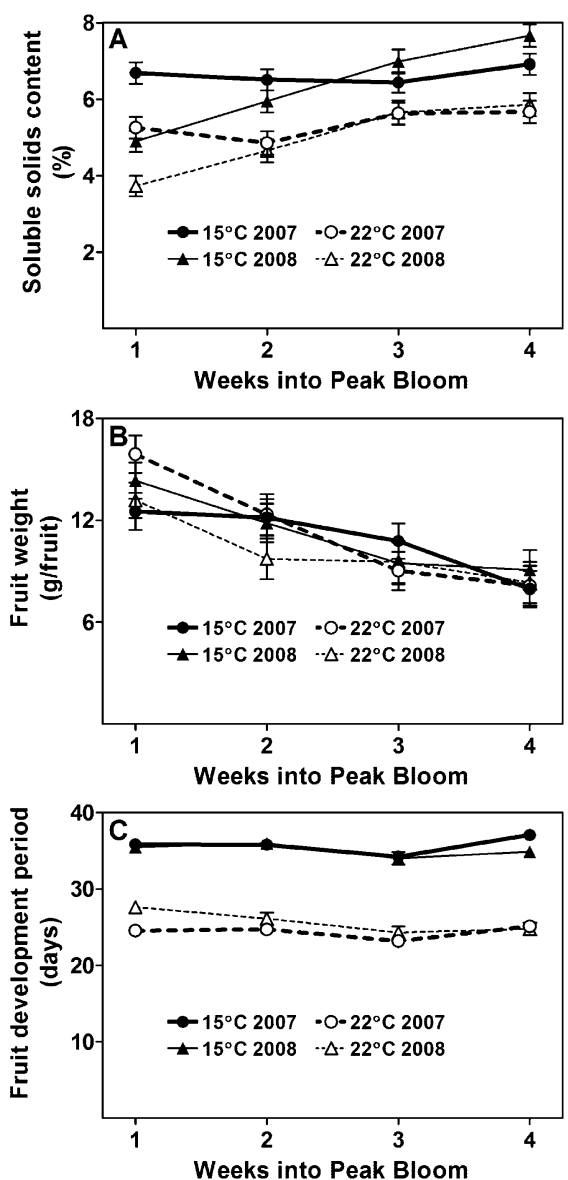

Fig. 2. Soluble solids content (\%) (A), fruit weight (g/fruit) (B), and fruit development period (days) (C) of 'Strawberry Festival' fruit from plants after transplantation from a field to each of two constant temperature environments on four dates separated by 1 week at the end of the 2007 and 2008 seasons. For each transplant date, the number of weeks that had passed since the beginning of the peak bloom is given by the variable weeks into peak bloom (WPB). Error bars represent SES. 
at higher temperatures, increased net photosynthesis during the day will not compensate for increased respiration at night and that concentrations of nonstructural carbohydrates in leaf tissues should decline. Sugar uptake to fruit tissues was shown to be unsaturated at concentrations present in plant tissues (Forney and Breen, 1986; Macías-Rodríguez et al., 2002); therefore, a reduction in the concentration of source sugars should contribute to reduced fruit SSC.

Previous studies reporting a negative correlation between temperature and SSC in strawberry either examined this phenomenon at one developmental stage (Wang and Camp, 2000) or did not consider changes in crop load over time (Hoppula and Karhu, 2006). During both years of our study there was a dramatic yield increase for 'Strawberry Festival' in the field as peak harvest progressed (Fig. 1). Increased fruit load may potentially affect fruit SSC by decreasing the source:sink ratio. However, because there was no decline in SSC under constant temperatures, such a conclusion cannot be made from this study. In the growth room experiment, the estimated yield covariate did not affect SSC and its inclusion did not change the significance level of any factors in the model.

Effect of weeks into peak bloom on fruit weight and fruit development period. In analyses using data from 2007 and 2008 combined, there was a linear, negative association between fruit weight and WPB that was similar during both years (Table 1; Fig. 2B). Although fruit were larger on average, a similar decline in fruit weight during the peak harvest was reported for 'Strawberry Festival' in the field, and the decline was attributed to lower-order fruit ripening later (Fig. 1; MacKenzie and Chandler, 2009). Temperature did not affect fruit weight. Although some studies report a correlation between fruit weight and temperature, results are not consistent. Hortyński et al. (1994) found that fruit weight was positively correlated with temperature during early fruit development and negatively correlated with temperatures at ripening. During other periods, temperature had little impact on fruit weight. Le Mière et al. (1998) showed that average berry weight was negatively correlated with temperature. The present study differed from these studies in that only temperature during fruit development beginning 3 to $5 \mathrm{~d}$ after flowers opened was altered, and the fruit that were compared underwent anthesis at about the same time. This could explain why no effect of temperature was observed.

Fruit development period was affected by temperature and WPB, and there was a significant year $\times$ temperature effect (Table 1; Fig. 2C). Temperature had the greatest impact on FDP both years $\left(15^{\circ} \mathrm{C}\right.$ FDP $=35.7 \mathrm{~d}$ in 2007 and $35.1 \mathrm{~d}$ in $2008 ; 22{ }^{\circ} \mathrm{C}$ FDP $=24.4 \mathrm{~d}$ in 2007 and $25.7 \mathrm{~d}$ in 2008). The observed effect of temperature on FDP $\left(-1.5 \mathrm{~d} /{ }^{\circ} \mathrm{C}\right)$ was close to that reported for a regression of FDPs on post-flowering mean 25 -d temperatures for fruit in the field (MacKenzie and Chandler, 2009). Although WPB affected FDP, the effect was small and there was no consistent trend

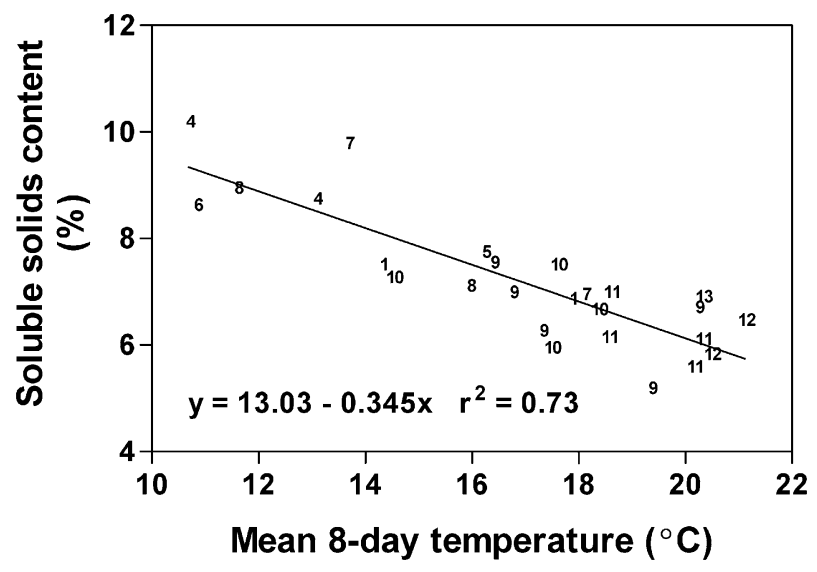

Fig. 3. The effect of the mean 8-d air temperature before harvest on mean soluble solids content (SSC) of 'Strawberry Festival' fruit observed during the months of January, February, and March over six seasons in Florida. Each plotted number indicates the number of weeks past 1 Jan. that the SSC value was determined.

evident (Fig. 2C). There was a 3-d period between when flowers were tagged and when they were placed into the constant temperature environment. Temperature differences during this interval coupled with the relatively low variation observed for FDP could explain why FDP was different between different WPBs. Also, in 2008, fruit from WPB 1 at $22^{\circ} \mathrm{C}$ were paler than other fruit when fully ripe. There was a delay in counting these fruit as ripe that explains the longer FDP for fruit in this category. This would contribute to the year $\times$ temperature effect and linear effect of WPB on FDP in 2008.

A model to predict fruit soluble solids content based on temperature. The highest coefficient of determination for a regression of SSC on mean temperature over an interval preceding harvest ( 1 to $21 \mathrm{~d}$ ) was for the 8 -d interval $\left(r^{2}=0.73\right)$. Solar radiation over any of the 21 intervals failed to account for variation in mean percent SSC when included in a regression with the temperature variable. The mean 8-d temperature preceding harvest was generally higher for harvests late in the year, although there were some exceptions. On dates when early harvests were preceded by relatively high temperatures and late harvests were preceded by relatively low temperatures, there was no evidence that fruit SSC deviated from values expected based on the 8-d temperature (Fig. 3). These results raise the possibility that growers could use atmospheric temperature forecasts to inform decisions on the pricing and marketing of strawberry fruit. In Finland, fruit SSC was negatively correlated with mean temperature over the period 2 weeks before harvest and positively correlated with radiation over this interval (Hoppula and Karhu, 2006). Shading has also been shown to reduce fruit sugars (Watson et al., 2002), and some of the data in Finland were taken from plants grown under a polyethylene cover. Fruit harvested from growth rooms had lower SSC values than expected based on the regression of fruit SSC on temperature in the field. Subsaturation levels of $P A R$ in the growth rooms likely accounts for this discrepancy. In Florida, during most daylight hours, light intensities approached or exceeded the threshold required for maximum photosynthesis (University of Florida, 2009; Yoshida and Morimoto, 1997). This would explain why no effect of solar radiation was observed in field-collected fruit when temperature was included in the model.

\section{Conclusions}

Despite a marked reduction of SSC in the field in 2007, progression of peak bloom did not result in a decrease in SSC under constant temperatures. During an uncharacteristic season in 2008 when SSC did not decrease in the field, SSC actually increased with the progression of peak harvest in the constant temperature environment. In both seasons, we observed lower mean SSC at $22^{\circ} \mathrm{C}$ compared with $15^{\circ} \mathrm{C}$. In addition, there was no evidence that an increase in crop load lowers SSC at constant temperatures. Based on these results, we reject the hypothesis that the progression of the peak harvest results in a decline of fruit SSC independent of temperature and conclude that temperature is a major factor responsible for the late-season decline in SSC of strawberry fruit in a subtropical production system. The mean 8-d temperature preceding harvest described a large proportion of the variance in fruit SSC and explained fruit SSC that was uncharacteristically high or low on particular harvest dates. The SSC decline may be explained by the sensitivity of individual components of strawberry sugar transport and metabolism to temperature.

\section{Literature Cited}

Blanke, M. 2002. Photosynthesis of strawberry fruit. Acta Hort. 567:373-376.

Chabot, B.F. 1978. Environmental influences on photosynthesis and growth in Fragaria vesca. New Phytol. 80:87-98.

Chandler, C.K., T.E. Crocker, J.F. Price, and E.E. Albregts. 1994. Growing strawberries in the Florida garden. Proc. Fla. State Hort. Soc. 107: 397-399.

Dana, M.N. 1980. The strawberry plant and its environment, p. 33-44. In: Childers, N.F. (ed.). 
The strawberry: Varieties, culture, pests and control, storage, marketing. Horticultural Publications, Gainesville, FL.

Del Pozo-Insfran, D., C.E. Duncan, K.C. Yu, S.T. Talcott, and C.K. Chandler. 2006. Polyphenolics, ascorbic acid, and soluble solids concentrations of strawberry cultivars and selections grown in a winter annual hill production system. J. Amer. Soc. Hort. Sci. 131:89-96.

Ferree, D.C. and E.J. Stang. 1988. Seasonal plant shading, growth, and fruiting in 'Earliglow' strawberry. J. Amer. Soc. Hort. Sci. 113:322-327.

Forney, C.F. and P.J. Breen. 1986. Sugar content and uptake in the strawberry fruit. J. Amer. Soc. Hort. Sci. 111:241-247.

Haller, M.H., D.H. Rose, and P.L. Harding. 1941. Studies on the respiration of strawberry and raspberry fruit. U.S. Dept. Agr. Circ. 613: $1-13$.

Hoppula, K.B. and S.T. Karhu. 2006. Strawberry fruit quality responses to the production environment. Intl. J. Food Agr. Environ. 4:166-170.

Hortyński, J.A., K. Liniewicz, and T. Hulewicz. 1994. Influence of some atmospheric factors affecting yield and single fruit weight in strawberry. J. Hort. Sci. 69:89-95.

Janick, J. and D.A. Eggert. 1968. Factors affecting fruit size in strawberry. Proc. Amer. Soc. Hort. Sci. 93:311-316.
Jouquand, C., C. Chandler, A. Plotto, and K. Goodner. 2008. A sensory and chemical analysis of fresh strawberries over harvest dates and seasons reveals factors that affect eating quality. J. Amer. Soc. Hort. Sci. 133:859-867.

Legard, D.E., S.J. MacKenzie, J.C. Mertely, C.K Chandler, and N.A. Peres. 2005. Development of a reduced use fungicide program for control of Botrytis fruit rot on annual winter strawberry. Plant Dis. 89:1353-1358.

Le Mière, P., P. Hadley, J. Darby, and N.H. Battey. 1998. The effect of thermal environment, planting date and crown size on growth, development and yield of Fragaria $\times$ ananassa Duch. cv. Elsanta. J. Hort. Sci. Biotechnol. 73:786795.

Macías-Rodríguez, L., E. Quero, and M.G. López. 2002. Carbohydrate differences in strawberry crowns and fruit (Fragaria $\times$ ananassa) during plant development. J. Agr. Food Chem. 50: 3317-3321.

MacKenzie, S.J. and C.K. Chandler. 2009. A method to predict weekly strawberry fruit yields from extended season production systems. Agron. J. 101:278-287.

Olsen, J.L., L.W. Martin, P.J. Pelofske, P.J. Breen, and C.F. Forney. 1985. Functional growth analysis of field grown strawberry. J. Amer. Soc. Hort. Sci. 110:89-93.
Perkins-Veazie, P. 1995. Growth and ripening of strawberry fruit. Hort. Rev. 17:267-297.

Saur, N. 2007. Molecular physiology of higher plant sucrose transporters. FEBS Lett. 581: 2309-2317.

Schaffer, B., J.A. Barden, and J.M. Williams. 1986. Whole plant photosynthesis and dry-matter partitioning in fruiting and deblossomed dayneutral strawberry plants. J. Amer. Soc. Hort. Sci. 111:430-433

U.S. Department of Agriculture. 2011. Noncitrus fruits and nuts 2010 summary. 23 Aug. 2011. $<$ http:/usda.mannlib.cornell.edu/usda/current/ NoncFruiNu/NoncFruiNu-07-07-2011.pdf $>$.

University of Florida. 2009. Florida Automated Weather Network: Report generator. 10 July 2009. <http://fawn.ifas.ufl.edu/data/reports/>.

Wang, S.Y. and M.J. Camp. 2000. Temperatures after bloom affect plant growth and fruit quality of strawberry. Sci. Hort. 85:183-199.

Watson, R., C.J. Wright, T. McBourney, A.J. Taylor, and R.S.T. Linforth. 2002. Influence of harvest date and light integral on the development of strawberry flavor compounds. J. Exp. Biol. 53:2121-2129.

Yoshida, Y. and Y. Morimoto. 1997. Measurement, modeling and seasonal changes of canopy photosynthesis in 'Nyoho' strawberry. Acta Hort. 439:575-582. 